\title{
Halogen Determination in Polymeric Waste of Electrical and Electronic Equipment: Overcoming Limitations in Sample Preparation
}

\author{
Jussiane S. Silva, ${ }^{a}$ Gabrielle D. Iop, ${ }^{a}$ Rodrigo M. Pereira, ${ }^{\circledR b}$ Marcia F. Mesko, ${ }^{\circledR b}$ \\ Lisarb O. Diehl, ${ }^{a}$ Erico M. M. Flores ${ }^{a}$ and Paola A. Mello ${ }^{\circledR *, a}$ \\ ${ }^{a}$ Departamento de Química, Universidade Federal de Santa Maria, \\ 97105-900 Santa Maria-RS, Brazil \\ ${ }^{b}$ Centro de Ciências Químicas, Farmacêuticas e de Alimentos, Universidade Federal de Pelotas, \\ 96010-610 Pelotas-RS, Brazil
}

\begin{abstract}
Sample preparation of polymers for halogen determination requires special attention because they are difficult to bring into solution and due to the risk of analyte losses when using acid digestion. A method using microwave-induced combustion (MIC) was optimized for accurate determination of halogens in polymeric parts obtained in waste of electrical and electronic equipment. Results were compared with those by using microwave-assisted extraction (MAE) with alkaline solution and microwave-assisted wet digestion (MAWD) using concentrated nitric acid, which are common choices for sample preparation. In this particular case, the MAE method was not suitable and underestimated results were obtained, showing the necessity for the complete digestion. Even with the use of MAWD under high temperature and pressure, incomplete digestion and high acid content were obtained, which were unsuitable for analysis and resulted in poor recovery. Only by using MIC (diluted ammonia as absorbing solution) acceptable recoveries (95 to 104\%) and agreement with certified values for the certified reference materials (CRMs) of polymers were obtained. Thus, a suitable method for all halogen to be determined by ion chromatography (IC) or inductively coupled plasma mass spectrometry (ICP-MS), with the exception of F, was obtained in agreement with the requirements by the Restriction of the Use of Certain Hazardous Substances (RoHS) European directive.
\end{abstract}

Keywords: e-waste, RoHS directive, halogens, ion chromatography, ICP-MS

\section{Introduction}

The amount of generated waste of electrical and electronic equipment (WEEE) has been rapidly growing due to continuous changes in technology and the expansion of the electronics industry. ${ }^{1}$ The hazardous components of those equipment make waste management difficult, and their recycling is commonly not performed efficiently. ${ }^{1,2}$ Thus, the European Union recently established the Restriction of the Use of Certain Hazardous Substances (RoHS) directive for electrical and electronic equipment. ${ }^{2}$ This directive establishes regulation of the management of wastes containing brominated flame retardants (BFRs) and metallic elements up to a certain maximum level. ${ }^{2}$

Halogenated flame retardants are widely used in the manufacture of electronic equipment, textiles,

*e-mail: paola.mello@ufsm.br polymers, and other materials for preventing fires. ${ }^{3}$ These substances are persistent, bioaccumulative, and toxic for the environment. ${ }^{4,5}$ In addition, they may enter the food chain, causing serious health risks. ${ }^{5-8}$ Furthermore, WEEE containing halogens can cause problems during incineration, such as the release of dioxins and respective halogenated acids. ${ }^{910}$ Thus, the RoHS directive sets the maximum concentrations of polybrominated biphenyl (PBB) and polybrominated diphenyl ether (PBDE) in specific materials and components of electrical and electronic equipment to $0.1 \%$. $^{2}$

In this respect, to monitor the BFRs present in WEEE, the development of feasible analytical methods is increasingly required. The determination of bromine from BFRs, such as PBB and PBDE, and other halogenated impurities contained in WEEE can be performed by ion chromatography (IC). This technique has been considered preferable for the determination of total halogens in 
routine analysis. ${ }^{11,12}$ Nevertheless, the analysis of WEEE by IC requires prior, effective sample digestion in order to obtain a solution suitable for the introduction into the equipment, one with low acidity, low carbon content, and without particles. ${ }^{12}$

Despite the great industrial and environmental relevance of the determination of halogens in WEEE, a few studies in the literature have concerned the development of digestion methods for polymeric materials and further halogens determination, ${ }^{9,11,13}$ possibly due to the difficulty of polymer digestion assuring a suitable recovery of halogens. Digestion of these materials is commonly performed under drastic conditions, such as high pressure and temperature with concentrated acids. ${ }^{14,15}$ In this sense, microwaveassisted wet digestion (MAWD) in closed vessels has been applied to biological, botanical, geological, environmental, and polymeric samples. ${ }^{14-16}$ In this system, high pressure and temperature can be used, resulting in high efficiency of digestion. ${ }^{17}$ However, the MAWD method is usually unsuitable for the determination of halogens, because it can lead to the generation and losses of volatile species, as well as high acid content in digests, which can interfere in determination step. ${ }^{13,18}$ On the other hand, microwaveassisted extraction (MAE) has been performed to extract halogens into aqueous solution, using alkaline reagents, such as ammonia and tetramethylammonium hydroxide (TMAH), under mild temperature (e.g., $\left.90{ }^{\circ} \mathrm{C}\right) .{ }^{19}$ However, MAE may not be enough for the complete extraction of halogens, particularly when they are present as organic compounds, resulting in underestimated values. ${ }^{19}$ If the final solution contains high amounts of organic compounds, they can also interfere in the determination leading to inaccurate results. ${ }^{19,20}$ After preparing samples, halogens determination can be performed by inductively coupled plasma mass spectrometry (ICP-MS), inductively coupled plasma optical emission spectrometry (ICP OES), or IC. ${ }^{11-13,19,20}$ Halogens determination in WEEE has also been performed by X-ray fluorescence analysis as an alternative, minimizing the sample preparation problems previously mentioned. ${ }^{21-23}$ However, this technique can require suitable standard materials for calibration, which are not easily available. ${ }^{9,24,25}$

In this sense, combustion systems would be preferable to digest polymeric samples for further halogens determination. ${ }^{9,24,26}$ These systems allow the complete combustion of the organic matrix and the use of diluted absorbing solutions to retain analytes. ${ }^{9,27}$ However, the classical combustion bomb and oxygen flask (Schöniger) systems are limited by their low sample throughput, and it is impossible to apply a reflux step to improve analyte recoveries. ${ }^{11-13,28}$ In order to overcome these drawbacks, a microwave-induced combustion (MIC) method was developed that allows the digestion of a relatively high sample mass using diluted absorbing solution and a reflux step. ${ }^{13,28}$ This system has been applied to the digestion of many materials, including elastomers ${ }^{11}$ for the further determination of halogens by IC and ICP-MS, as well as plastics (low- and high-density polyethylene, polypropylene, polystyrene, polyethylene terephthalate, polyetheretherketone, and nylon 6.6$)^{29}$ for metals determination by ICP-MS and ICP OES. Despite the successful application of MIC for these polymers, this method ${ }^{29}$ was still not evaluated for halogens determination.

Considering the need for methods allowing suitable digestion of polymeric WEEE for halogens determination, in the present work, a method was optimized to circumvent the limitations of common methods for sample preparation of polymers for halogens determination. A method using MIC was optimized and results were compared with those using MAE and MAWD. Sample preparation methods were evaluated in terms of digestion efficiency, suitability of digests for IC or ICP-MS analysis and accuracy. The following operational conditions related to MIC were studied, including sample mass and different types and concentrations of absorbing solution: $\mathrm{H}_{2} \mathrm{O}, 0.02$ to $0.90 \mathrm{mmol} \mathrm{L}^{-1} \mathrm{H}_{2} \mathrm{O}_{2}, 10$ to $100 \mathrm{mmol} \mathrm{L}^{-1}$ ammonia solution, and 10 to $100 \mathrm{mmol} \mathrm{L}^{-1}$ $\left(\mathrm{NH}_{4}\right)_{2} \mathrm{CO}_{3}$. The suitability of digests for IC and ICP-MS analyses (carbon content and final $\mathrm{pH}$ ) was also evaluated. The accuracy was evaluated using certified reference materials (CRMs) of low-density polyethylene. Recovery experiments were performed for $\mathrm{F}, \mathrm{Cl}, \mathrm{Br}$, and I. In addition, polymeric parts segregated from WEEE (optical mouse, remote control of an air conditioner, keyboard, and mobile phone) were used as samples, submitted to the MIC method for further determination of halogens by IC.

\section{Experimental}

Instrumentation

Polymeric parts of WEEE were ground using a cryogenic mill (Spex Certiprep 6750, USA) and dried in an oven (Nova Ética 400 / 2ND, Brazil). An analytical balance (Shimadzu AY220, Brazil) was used to weigh the samples. A hydraulic press (13 mm diameter, set at $3 \mathrm{t}$, Specac, UK) was used to press the samples as pellets for MIC.

A microwave-assisted sample preparation system (Anton Paar Multiwave 3000, Austria) equipped with up to eight closed quartz vessels (internal volume of $80 \mathrm{~mL}$, maximum temperature and pressure of $280{ }^{\circ} \mathrm{C}$ and $80 \mathrm{bar}$, respectively) was used for MAE, MAWD, and MIC methods. For the combustion process, commercial quartz holders (Anton Paar, part No. 16427, Austria) were used. 
Halogens determination was performed using an IC system (Metrohm 850 Professional IC, Switzerland) with conductivity detection. It was equipped with an anion-exchange column (Metrosep A Supp 5, Metrohm, Switzerland, polyvinylalcohol with quaternary ammonium groups, $250 \times 4 \mathrm{~mm}$ i.d., $5 \mu \mathrm{m}$ ), a guard column (Metrosep A Supp 4 / 5 Guard, Metrohm, Switzerland), and a chemical and self-regeneration suppressor module. The selected mobile phase was $3.2 \mathrm{mmol} \mathrm{L}^{-1} \mathrm{Na}_{2} \mathrm{CO}_{3}$ and $1.0 \mathrm{mmol} \mathrm{L}^{-1} \mathrm{NaHCO}_{3}$ at a flow rate of $0.7 \mathrm{~mL} \mathrm{~min}^{-1} .{ }^{12} \mathrm{~A}$ sample loop of $100 \mu \mathrm{L}$ was used.

For the determination of $\mathrm{Cl}, \mathrm{Br}$, and I, an ICP-MS (PerkinElmer-SCIEX Elan DRC II, Canada) equipped with a concentric nebulizer and a baffled cyclonic spray chamber was also used. Isotopes were ${ }^{35} \mathrm{Cl},{ }^{79} \mathrm{Br}$, and ${ }^{127} \mathrm{I}$. Regarding the plasma operational conditions used in the ICP-MS, radio-frequency power was $1300 \mathrm{~W}$ and argon flow rates of plasma, auxiliary, and nebulizer, were 15.0, 1.2 and $1.05 \mathrm{~L} \mathrm{~min}^{-1}$, respectively, according to previous works. ${ }^{11,19,28,30}$ For chlorine, the determination was carried out by using the dynamic reaction cell following the operational conditions optimized by Antes et al. ${ }^{30} \mathrm{In}$ order to evaluate digestion efficiency, the carbon content in the digests was determined by ICP OES (PerkinElmer Optima 4300 DV, USA) using a GemCone ${ }^{\circledR}$ nebulizer and a cyclonic spray chamber. Wavelengths were set at 193.091 and $371.029 \mathrm{~nm}$ for carbon and yttrium (used as internal standard), respectively. ${ }^{31}$ Operational conditions of ICP OES were as follows: radio-frequency power of $1400 \mathrm{~W}$, plasma gas flow rate of $15.0 \mathrm{~L} \mathrm{~min}^{-1}$, auxiliary gas flow rate of $0.2 \mathrm{~L} \mathrm{~min}^{-1}$, and nebulizer gas flow rate of $0.70 \mathrm{~L} \mathrm{~min}^{-1}{ }^{13,29}$ Argon (99.998\%, White Martins-Praxair, Brazil) was used to generate plasma, for nebulization, as an auxiliary gas, for cryogenic milling, and also to remove carbonaceous gases dissolved into digests before determining the carbon content.

\section{Reagents, samples, and sample preparation}

Ultrapure water from a Milli-Q system $(18.2 \mathrm{M} \Omega \mathrm{cm}$, Millipore, USA) was used to dilute and prepare all standard solutions, mobile phase, and reagents. Ammonium nitrate $\left(\mathrm{NH}_{4} \mathrm{NO}_{3}\right.$, Merck, Darmstadt, Germany) was used to prepare a $6 \mathrm{~mol} \mathrm{~L}^{-1}$ solution that was used as igniter for MIC. An ammonia solution $\left(25 \% \mathrm{NH}_{3}\right.$ in water, Merck, Darmstadt, Germany) was used to prepare absorbing solutions for combustion and the extraction process. Ammonium carbonate $\left(\left(\mathrm{NH}_{4}\right)_{2} \mathrm{CO}_{3}\right.$, Merck, Darmstadt, Germany) and hydrogen peroxide (30\%, Vetec, Rio de Janeiro, Brazil) were also used to prepare the absorbing solutions for MIC. Alkaline extraction was performed with TMAH (0.1 mol L-1, Merck, Darmstadt, Germany). Concentrated nitric acid (65\%, $\mathrm{HNO}_{3}$, Merck, Darmstadt, Germany) was distilled using a sub-boiling system (Milestone DuoPur, Italy) and used for MAWD. For calibration, analytical solutions of halogens $(\mathrm{F}, \mathrm{Cl}$, and $\mathrm{Br}$ ) were prepared from a multielement anion standard solution (10 $\mathrm{mg} \mathrm{L}^{-1}$, Fluka, St. Louis, USA) in water for IC and in diluted $\mathrm{NH}_{3}\left(10 \mathrm{mmol} \mathrm{L}^{-1}\right)$ for ICP-MS. A stock standard solution of iodine $\left(1000 \mathrm{mg} \mathrm{L}^{-1}\right)$ was prepared by dissolving potassium iodide salt (Merck, Darmstadt, Germany) in water. For carbon determination by ICP OES, standard solutions were prepared by successive dilution of a stock solution (1000 $\left.\mathrm{mg} \mathrm{L}^{-1}\right)$, which was prepared using citric acid (Merck, Darmstadt, Germany) dissolved in water. A standard solution of yttrium (1 mg L-1, Fluka, St. Louis, USA) was used as the internal standard.

An optical mouse, remote control of an air conditioner, keyboard, and a mobile phone were used as WEEE examples. The metallic and polymeric parts of WEEE were manually separated and the polymeric parts were used in this work (more information is available in Figure S1, Supplementary Information (SI) section). For all samples, the main composition of polymers was obtained by infrared spectroscopy analysis (PerkinElmer Spectrum One FTIR, USA) showing that WEEE are based on acrylonitrile butadiene styrene (ABS) copolymer, polycarbonate / ABS blend, polyurethane / styrene acrylonitrile copolymer, polyester, polystyrene and polypropylene, as seen in previous literature. ${ }^{1}$ Samples were ground in a cryogenic mill by applying a pre-cooling time of $90 \mathrm{~s}$ followed by 3 min for grinding, repeated three times. As particle size can influence sample preparation, particularly impairing extraction efficiency, it was measured and was between 20 and $300 \mu \mathrm{m}$. Ground samples were dried at $60^{\circ} \mathrm{C}$ for $1 \mathrm{~h}$ in an oven. Polymeric parts segregated from an optical mouse were used to optimize parameters. In view of the lack of CRMs of WEEE with certified values for all analytes (F, $\mathrm{Cl}, \mathrm{Br}$ and I), accuracy was verified using analyte addition and CRMs provided by European Reference Materials (ERM, Geel, Belgium) of low-density polyethylene (ERM EC 680k and ERM EC 681k).

\section{Experimental procedures}

\section{MAE}

Polymeric parts from the optical mouse (an ABS copolymer-based matrix) were used as a model polymer from WEEE for digestion by all methods. Sample masses of $300 \mathrm{mg}$ were weighed and transferred to the quartz vessels, after which $6 \mathrm{~mL}$ of $50 \mathrm{mmol} \mathrm{L}^{-1}$ ammonia solution or $0.11 \mathrm{~mol} \mathrm{~L}^{-1} \mathrm{TMAH}$ were added according to previous 
works for halogens in food and biological samples. ${ }^{28,32,33}$ The irradiation program for MAE was $1400 \mathrm{~W}$ for $25 \mathrm{~min}$ with $10 \mathrm{~min}$ ramp and $20 \mathrm{~min}$ for cooling. The maximum temperature of the irradiation program was set to $90{ }^{\circ} \mathrm{C}$ in order to avoid the possibility of TMAH degradation. ${ }^{32}$ The final solution after irradiation was collected and diluted with water up to $25 \mathrm{~mL}$ for determination by IC and ICP-MS.

\section{MAWD}

Sample masses of $350 \mathrm{mg}$ were weighed into the quartz vessels, and $6 \mathrm{~mL}$ of concentrated $\mathrm{HNO}_{3}$ were added based on the conditions previously reported for metals in polymers. ${ }^{29,31}$ Hydrochloric acid was not used in this case taking into account the determination of chlorine. The irradiation program was similar to the MAE method (1400 W for 25 min with $10 \mathrm{~min}$ ramp and $20 \mathrm{~min}$ for cooling), but the maximum temperature was set to $280^{\circ} \mathrm{C}$. After the microwave program, the resulting solution was transferred to volumetric vessels and diluted with water up to $25 \mathrm{~mL}$ for further determination by ICP-MS.

MIC

In order to evaluate the operational conditions of MIC, polymeric WEEE was prepared as 100, 200, 300, and $350 \mathrm{mg}$ sample pellets. The pellets were placed on the quartz holder with a disc of filter paper along with $50 \mu \mathrm{L}$ of $6 \mathrm{~mol} \mathrm{~L}^{-1} \mathrm{NH}_{4} \mathrm{NO}_{3}$ solution. The quartz holder was introduced into the quartz vessel with $6 \mathrm{~mL}$ of absorbing solution. Then, the vessels were pressurized with 20 bar of oxygen. The irradiation program was $1400 \mathrm{~W}$ for $5 \mathrm{~min}$ and $20 \mathrm{~min}$ for cooling. The reflux step after combustion was performed in accordance with previous works. ${ }^{11,13}$ After digestion, the pressure of each vessel was carefully released, and the resulting solution was collected and diluted with water up to $25 \mathrm{~mL}$ for further determination by IC or ICP-MS. Cleaning of vessels and holders was performed in two steps: first, $6 \mathrm{~mL}$ of concentrated $\mathrm{HNO}_{3}$, followed by another step with $6 \mathrm{~mL}$ of $\mathrm{H}_{2} \mathrm{O}$. After both steps, an irradiation program at $1000 \mathrm{~W}$ for $10 \mathrm{~min}$ and cooling for 20 min was applied.

Figure 1 summarizes the methods evaluated for further determination of halogens in polymeric WEEE by IC or ICP-MS.

\section{Results and Discussion}

Sample preparation methods for polymeric WEEE: limitations and optimization

\section{MAE}

Alkaline reagents, such as TMAH or $\mathrm{NH}_{3}$ solutions combined with microwave radiation have been used in sample preparation for further halogens determination. ${ }^{20,34,35}$ In spite of successful applications for some matrices, as food and biological samples, using conventional heating ${ }^{35,36}$ or microwave heating ${ }^{19,20,34}$ for the case of polymers, these procedures cannot assure total digestion or dissolution of matrix and even analyte extraction must be investigated.

\section{WEEE (optical mouse, remote control of an air conditioner, keyboard and mobile phone)}

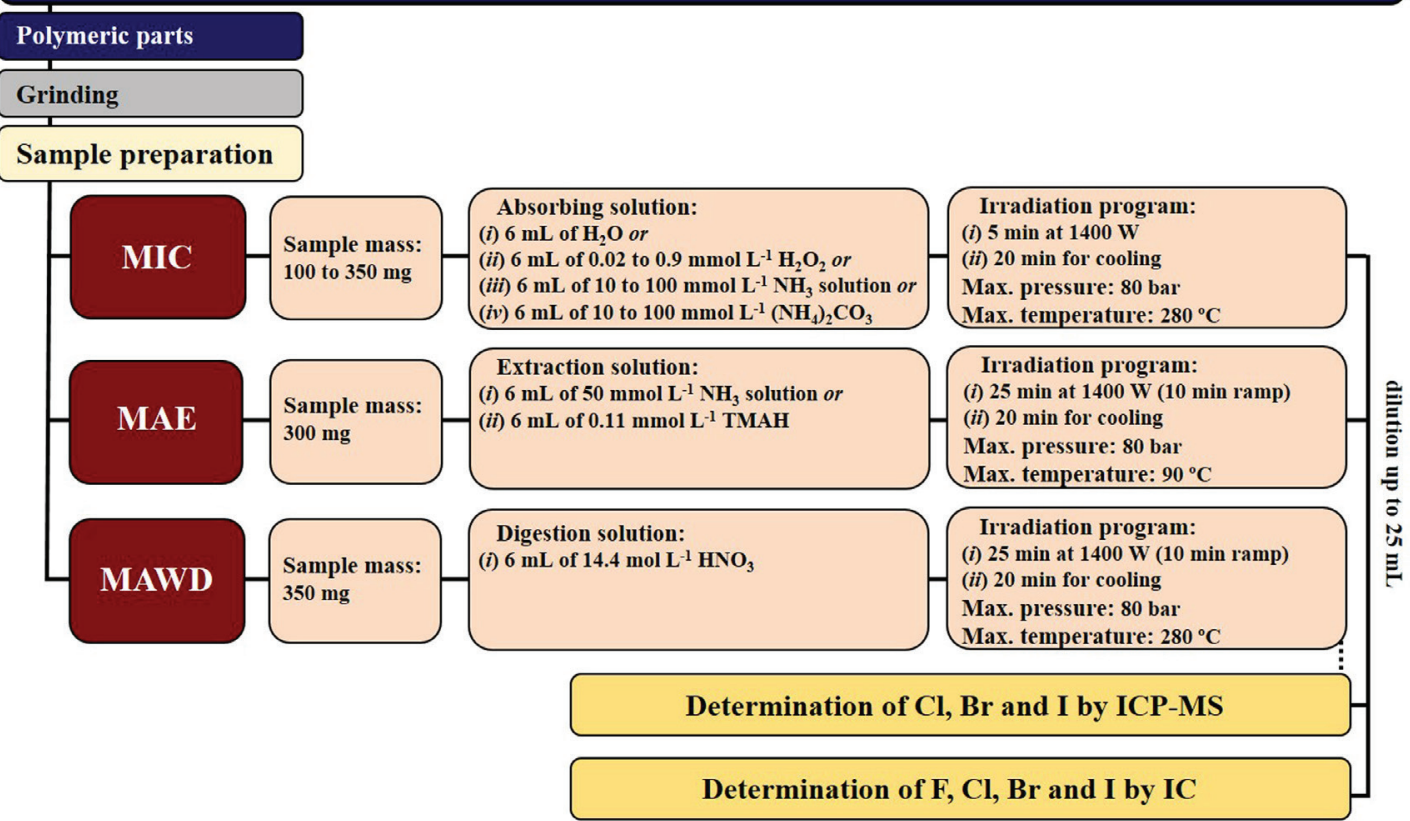

Figure 1. Sample preparation methods evaluated for the determination of halogens in polymeric WEEE. 
In the present work, MAE using $6 \mathrm{~mL}$ of $50 \mathrm{mmol} \mathrm{L}^{-1} \mathrm{NH}_{3}$ or $0.11 \mathrm{~mol} \mathrm{~L}^{-1} \mathrm{TMAH}$ solutions was evaluated for the extraction of halogens for further determination by IC or ICP-MS. After the irradiation program, final solutions were yellowish and presented solid residues for both extraction solutions (Figure 2a). Due to the presence of solid residues in the digests, the carbon content could not be determined, since underestimated results might be obtained. In order to prevent damage to the IC system, digests were filtered and diluted at least five times in water prior to analysis. For ICP-MS, filtration and a five times dilution in diluted $\mathrm{NH}_{3}$ solution $\left(10 \mathrm{mmol} \mathrm{L}^{-1}\right)$ was used to avoid also interferences due to the carbon content and due to memory effects in the nebulization chamber (for I). ${ }^{37}$

Results obtained for the polymeric WEEE (from the optical mouse) using $50 \mathrm{mmol} \mathrm{L}^{-1} \mathrm{NH}_{3}$ or $0.11 \mathrm{~mol} \mathrm{~L}^{-1}$ TMAH solutions, presented maximum agreement of $60 \%$ for $\mathrm{Cl}$ (in relation to the value obtained by MIC, $19 \mu \mathrm{g} \mathrm{g}^{-1}$, as will be further discussed). With regard to $\mathrm{Br}$ quantification after MAE, results were lower than the limit of quantification (LOQ) by IC $\left(4.2 \mu \mathrm{g} \mathrm{g}^{-1}\right)$ and ICP-MS $\left(0.4 \mu \mathrm{g} \mathrm{g}^{-1}\right)$ even though the results obtained by MIC were about $12 \mu \mathrm{g} \mathrm{g}^{-1}$. Results for F and I after MAE were lower than the LOQ by IC ( 4.3 and $18.3 \mu \mathrm{g} \mathrm{g}^{-1}$, respectively) and ICP-MS (only for I, $0.04 \mu \mathrm{g} \mathrm{g}^{-1}$ ). These results confirm the poor extraction efficiency for bromine and chlorine. Also, LOQs were increased and were unsuitable for other halogens, being impaired by the composition of MAE digests with solid residues and dissolved carbon, requiring additional dilutions.

The incomplete extraction using MAE, in particular for $\mathrm{Cl}$ and $\mathrm{Br}$ in the investigated samples, can be explained since mainly water-soluble species are expected to be extracted by this method. However, these analytes are commonly present as organic molecules in polymers, thus leading to poor extraction efficiency and consequently lower results were obtained using this method. ${ }^{31,38}$ Another important aspect to be considered is that samples containing mainly halogenated organic compounds require digestion to be detected by conductivity and this was not reached by this method. ${ }^{11,39}$ Therefore, MAE could not be considered appropriate for further halogens determination in WEEE. This was also confirmed by the poor agreement with certified values for CRMs (about 10\% for $\mathrm{Cl}$ and $20 \%$ for $\mathrm{Br}$ ) using MAE as sample preparation method.

\section{MAWD}

MAWD with nitric acid was evaluated looking for a complete destruction of the polymeric matrix from WEEE for further halogens determination. This method is a common choice in several laboratories since by using concentrated acids combined with high temperature and pressure, good digestion efficiency can be obtained for many matrices. ${ }^{40-43}$ It is important to highlight that polymers are difficult to digest, with harsh conditions (high amounts of acid, high temperature, and long digestion time) commonly required. ${ }^{11,13,29}$ However, the method was proven to be unsuitable for halogens due to the possibility of losses, even in closed systems. ${ }^{13}$ In this study, the method was investigated based on its suitability for polymers digestion in previous works for metals determination. ${ }^{913,29,44-46}$ Digestion was carried out using $350 \mathrm{mg}$ of polymeric WEEE (optical mouse) and concentrated $\mathrm{HNO}_{3}\left(14.4 \mathrm{~mol} \mathrm{~L}^{-1}\right)$.

After the irradiation program, solid residues in digests were observed and the solution was yellowish (Figure 2b). Carbon content was not determined because results could be underestimated by the amount of non-digested sample. Centrifugation and filtration were necessary before analysis. In addition, as digests containing high acid concentration are incompatible with the anion-exchange separation column of IC, ${ }^{12}$ ICP-MS technique was used for $\mathrm{Cl}, \mathrm{Br}$, and I determination. As a consequence, fluorine determination was not possible by using acid digestion.
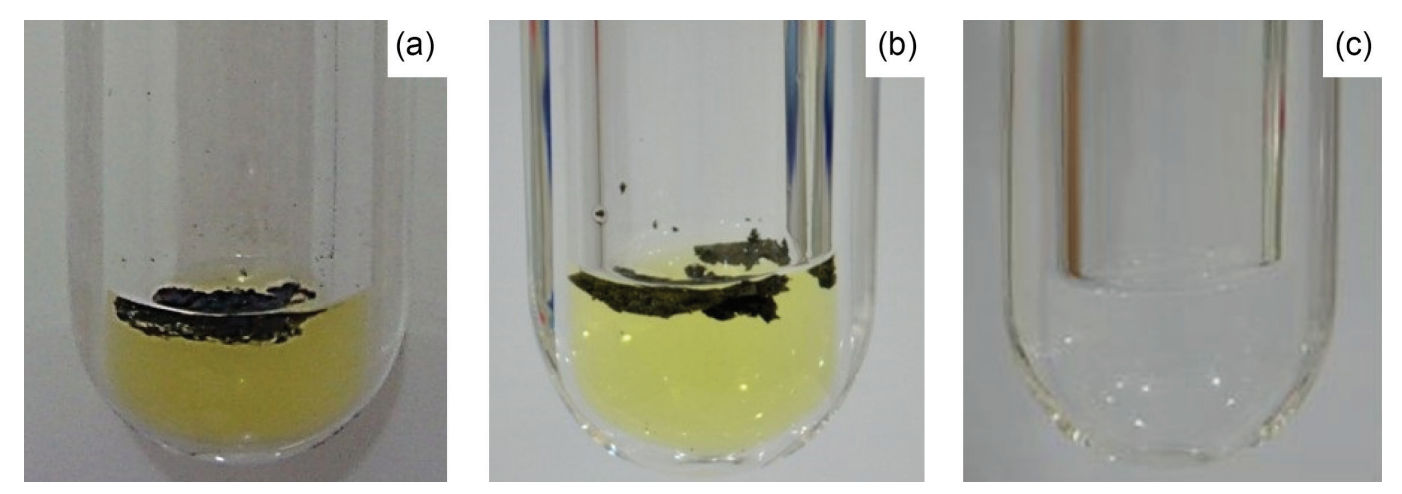

Figure 2. Visual aspect of final solutions after digestion of polymeric WEEE by (a) MAE, using $300 \mathrm{mg}$ of sample and $6 \mathrm{~mL}$ of diluted $\mathrm{NH}_{3}\left(50 \mathrm{mmol} \mathrm{L}^{-1}\right)$ as extraction solution; (b) MAWD, using $350 \mathrm{mg}$ of sample and $6 \mathrm{~mL}$ of $14.4 \mathrm{~mol} \mathrm{~L}^{-1} \mathrm{HNO}_{3}$ as digestion solution; and (c) MIC, using $300 \mathrm{mg}$ of sample and $6 \mathrm{~mL}$ of diluted $\mathrm{NH}_{3}\left(50 \mathrm{mmol} \mathrm{L}^{-1}\right)$ as absorbing solution. 
Dilution (at least twenty times) and neutralization steps were required to adjust the digests to the conditions of analysis (10 $\mathrm{mmol} \mathrm{L}^{-1} \mathrm{NH}_{3}$ solution).

The results for $\mathrm{Cl}$ and $\mathrm{I}$ were lower than the LOQ (1.2 $\mathrm{mg} \mathrm{g}^{-1}$ and $0.16 \mu \mathrm{g} \mathrm{g}^{-1}$, respectively). For $\mathrm{Br}$, the result by ICP-MS was $1.72 \pm 0.47 \mu \mathrm{g} \mathrm{g}^{-1}$, being lower than that obtained using other method investigated in this study (MIC, $12 \mu \mathrm{g} \mathrm{g}^{-1}$ ). Moreover, the results for $\mathrm{Cl}$ and $\mathrm{Br}$ for the ERM EC $681 \mathrm{k}$ were lower than the certified values and agreement was about 46 and 51\%, respectively. Also, relative standard deviation (RSD) was about $30 \%$ using this method. Considering the lower results for $\mathrm{Cl}$ and $\mathrm{Br}$ obtained by ICP-MS after MAWD, it is possible to suppose that the acid digestion led to losses of volatile species, such as $\mathrm{HCl}$ and $\mathrm{HBr}$, as reported in previous works. ${ }^{13,47}$ Considering the results, this method was considered not feasible as an alternative for digestion of polymers from WEEE for further halogens determination.

MIC

MIC was evaluated in this study for the digestion of polymeric WEEE for further determination of halogens by IC and ICP-MS (only for $\mathrm{Cl}, \mathrm{Br}$ and I). Previous evaluation of other methods demonstrated the inherent problems, such as: (i) poor extraction efficiency using alkaline solutions, considered suitable for halogens, as reported for food and biological matrices; (ii) the requirement of a high amount of acid to obtain complete digestion and the consequent non-compatibility of digests with IC and with conventional nebulization in ICP-MS due to memory effects (particularly for iodine); and (iii) the risk of halogens losses by volatilization. In this way, the suitability of the MIC method was investigated for further halogens determination.

To optimize the combustion and safety conditions during digestion, previous experiments were performed using masses of polymeric WEEE in the range of 100 to $350 \mathrm{mg}$ with 20 bar of oxygen. The oxygen pressure and conditions for MIC followed previous works regarding the digestion of samples with similar matrices. ${ }^{11,13,29}$ For sample masses of 100, 200 and $300 \mathrm{mg}$, combustion was complete; solid residues were not observed (Figure 2c). However, when $350 \mathrm{mg}$ were used, digestion was incomplete, probably due to the presence of flame retardants in these samples. ${ }^{13}$ Using sample masses up to $300 \mathrm{mg}$, the maximum pressure was only 28 bar, corresponding to $35 \%$ of the maximum working pressure recommended by the equipment manufacturer ( 80 bar). Therefore, a sample mass of $300 \mathrm{mg}$ was selected for subsequent experiments.

The choice of absorbing solution is important, affecting the ability to obtain suitable recoveries and to guarantee compatibility with the determination technique. In this sense, water, hydrogen peroxide, and alkaline solutions have all been reported in the literature for halogens determination after digestion by MIC for many matrices. ${ }^{12}$ In the present study, therefore, $\mathrm{H}_{2} \mathrm{O}, \mathrm{H}_{2} \mathrm{O}_{2}(0.02,0.2$ and $\left.0.9 \mathrm{mmol} \mathrm{L}^{-1}\right)$, diluted $\mathrm{NH}_{3}\left(10,50\right.$ and $\left.100 \mathrm{mmol} \mathrm{L}^{-1}\right)$, and $\left(\mathrm{NH}_{4}\right)_{2} \mathrm{CO}_{3}\left(10,50\right.$ and $\left.100 \mathrm{mmol} \mathrm{L}^{-1}\right)$ were evaluated as absorbing solutions.

With regard to the determinations by $\mathrm{IC}$, the chromatograms obtained using $\mathrm{H}_{2} \mathrm{O}, \mathrm{H}_{2} \mathrm{O}_{2}(0.02,0.2$ and $\left.0.9 \mathrm{mmol} \mathrm{L}^{-1}\right)$, diluted $\mathrm{NH}_{3}\left(10\right.$ and $\left.50 \mathrm{mmol} \mathrm{L}^{-1}\right)$, and $\left(\mathrm{NH}_{4}\right)_{2} \mathrm{CO}_{3}\left(10 \mathrm{mmol} \mathrm{L}^{-1}\right)$ as absorbing solution, presented retention times $\left(\mathrm{t}_{\mathrm{R}}\right)$ for $\mathrm{Cl}$ and for $\mathrm{Br}$ close to those found when using the reference solution $\left(100 \mu \mathrm{g} \mathrm{L}^{-1}\right)$ in $\mathrm{H}_{2} \mathrm{O}$. In this case, the $t_{R}$ for $\mathrm{Cl}$ and $\mathrm{Br}$ were 9.6 and $14.1 \mathrm{~min}$, respectively. On the other hand, when using $100 \mathrm{mmol} \mathrm{L}^{-1}$ $\mathrm{NH}_{3}$ or $50 \mathrm{mmol} \mathrm{L}^{-1}\left(\mathrm{NH}_{4}\right)_{2} \mathrm{CO}_{3}$ solutions, the $\mathrm{t}_{\mathrm{R}}$ for $\mathrm{Cl}$ and Br were delayed to 10.0 and $14.5 \mathrm{~min}$, respectively, for both solutions. In order to overcome this problem and to check the $\mathrm{t}_{\mathrm{R}}$ for $\mathrm{Cl}$ and $\mathrm{Br}$ signals, a reference solution containing $100 \mu \mathrm{g} \mathrm{L}^{-1} \mathrm{Cl}$ and $\mathrm{Br}$ was prepared in the same medium as the digests $\left(100 \mathrm{mmol} \mathrm{L}^{-1} \mathrm{NH}_{3}\right.$ and $50 \mathrm{mmol} \mathrm{L}^{-1}\left(\mathrm{NH}_{4}\right)_{2} \mathrm{CO}_{3}$ solutions). The $\mathrm{t}_{\mathrm{R}}$ for the $\mathrm{Cl}$ and $\mathrm{Br}$ in reference solutions and those obtained from the digests with $100 \mathrm{mmol} \mathrm{L}^{-1}$ $\mathrm{NH}_{3}$ and $50 \mathrm{mmol} \mathrm{L}^{-1}\left(\mathrm{NH}_{4}\right)_{2} \mathrm{CO}_{3}$ solutions were similar (98 to $100 \%$ ). This clearly shows that close similarity between reference solution and digests was achieved as a consequence of the practically complete matrix destruction using MIC. This efficiency was not reached in the other methods that also presented problems with recovery and poor extraction efficiency.

The results for $\mathrm{F}$ and I were lower than the LOQ by IC (0.90 and $1.50 \mu \mathrm{g} \mathrm{g}^{-1}$, respectively) in all analysed samples. Using ICP-MS they were lower than the LOQ for $\mathrm{I}\left(0.008 \mu \mathrm{g} \mathrm{g}^{-1}\right)$. When 10,50 , and $100 \mathrm{mmol} \mathrm{L}^{-1}\left(\mathrm{NH}_{4}\right)_{2} \mathrm{CO}_{3}$ solutions were used, the results for $\mathrm{Cl}$ were about $19 \mu \mathrm{g} \mathrm{g}^{-1}$ and the differences were not statistically significant for these concentrations (analysis of variance (ANOVA), 95\% confidence level). The $\mathrm{Br}$ concentration measured in the optical mouse sample using 10 and $50 \mathrm{mmol} \mathrm{L}^{-1}\left(\mathrm{NH}_{4}\right)_{2} \mathrm{CO}_{3}$ solutions were about $11 \mu \mathrm{g} \mathrm{g}^{-1}$ (difference not statistically significant, $t$-test, $95 \%$ confidence level). With the use of $100 \mathrm{mmol} \mathrm{L}^{-1}\left(\mathrm{NH}_{4}\right)_{2} \mathrm{CO}_{3}$ solution, the quantification of $\mathrm{Br}$ by IC after MIC was not possible due to the presence of an interference close to the $t_{R}$ of the analyte signal. As results using ammonium carbonate solutions were similar to those using ammonium hydroxide solutions, and both were suitable to $\mathrm{IC}$, only diluted $\mathrm{NH}_{3}$ was considered for other studies, also taking into account the necessity for alkaline solutions for ICP-MS nebulization system, in the case of halogens determination. 
The $\mathrm{Cl}$ and $\mathrm{Br}$ concentrations obtained by IC after MIC digestion using $\mathrm{H}_{2} \mathrm{O}, 0.02,0.2$, and $0.9 \mathrm{mmol} \mathrm{L}^{-1} \mathrm{H}_{2} \mathrm{O}_{2}$, and diluted $\mathrm{NH}_{3}\left(10,50\right.$, and $\left.100 \mathrm{mmol} \mathrm{L}^{-1}\right)$ as absorbing solutions are shown in Figure 3 (results for fluorine and iodine are not shown since they were lower than the LOQ). Results for $\mathrm{Cl}$ were between 18.9 and $19.6 \mu \mathrm{g} \mathrm{g}^{-1}$ with RSD in the range of 3 to $8 \%$. No statistical differences (ANOVA, 95\% confidence level) were observed between the results using $\mathrm{H}_{2} \mathrm{O}, \mathrm{H}_{2} \mathrm{O}_{2}$, and $\mathrm{NH}_{3}$ solution for $\mathrm{Cl}$. Regarding $\mathrm{Br}$, results were between 8.71 and $11.8 \mu \mathrm{g} \mathrm{g}^{-1}$, with RSD in the range of 4 to $12 \%$. Lower results were found for $\mathrm{Br}$ using $\mathrm{H}_{2} \mathrm{O}$ and $0.02 \mathrm{mmol} \mathrm{L}^{-1} \mathrm{H}_{2} \mathrm{O}_{2}$ in comparison to the values using alkaline solutions $\left(\mathrm{NH}_{3}\right.$ solutions, from 10 to $100 \mathrm{mmol} \mathrm{L}^{-1}$ ), indicating possible losses of $\mathrm{Br}$. Higher concentration was obtained using more concentrated $\mathrm{H}_{2} \mathrm{O}_{2}$ solutions $\left(0.2\right.$, and $\left.0.9 \mathrm{mmol} \mathrm{L}^{-1}\right)$ or alkaline solutions $(10$, 50, and $100 \mathrm{mmol} \mathrm{L}^{-1} \mathrm{NH}_{3}$ solutions) and no statistical differences (ANOVA, 95\% confidence level) were found among the results for $\mathrm{Br}$ using these absorbing solutions (Figure 3).

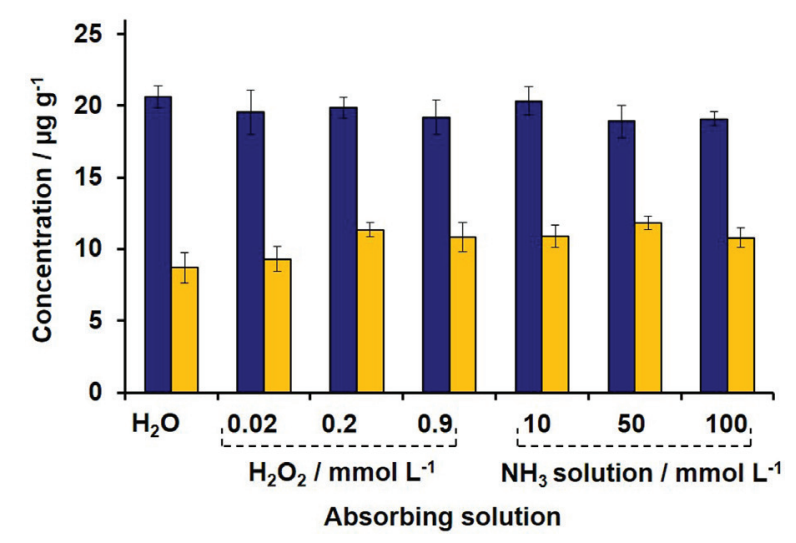

Figure 3. Influence of the absorbing solution on $\mathrm{Cl}(\square)$ and $\mathrm{Br}(\square)$ determination in polymeric WEEE (from optical mouse) after digestion by MIC. Determinations by IC (mean \pm standard deviation in $\mu \mathrm{g} \mathrm{g}^{-1}, \mathrm{n}=3$ ).

In order to evaluate the recoveries of halogens for all absorbing solutions, a spike solution was added on sample pellet before combustion ( $30 \mu \mathrm{L}$ of a $100 \mathrm{mg} \mathrm{L}^{-1}$ standard solution for $\mathrm{F}$ and $6 \mu \mathrm{L}$ of a $1000 \mathrm{mg} \mathrm{L}^{-1}$ standard solution for $\mathrm{Cl}, \mathrm{Br}$, and I). In spite of this approach not representing a fully reliable protocol to evaluate accuracy, spike recovery experiments for all the analytes were performed since no CRM is available with the same sample matrix containing halogens ( $\mathrm{F}, \mathrm{Cl}, \mathrm{Br}$ and I). Results obtained for halogens by IC after MIC digestion of the polymeric WEEE sample are shown in Figure 4. As can be seen, recoveries for $\mathrm{F}$ and $\mathrm{Cl}$ were 98 and $101 \%$, respectively, using water as the absorbing solution, with RSD values from 8 to $10 \%$. However, recoveries for $\mathrm{Br}$ and I were lower than 80 and $50 \%$, respectively, impairing its use for the determination of all halogens in the same run. With the use of $10 \mathrm{mmol} \mathrm{L}^{-1}$ $\mathrm{NH}_{3}$ solution, recoveries between 94 and $104 \%$ were obtained for $\mathrm{F}, \mathrm{Cl}$ and $\mathrm{Br}$ with RSDs lower than $8 \%$. However, this solution was not suitable for I since the recovery was only around $61 \%$. When 25 and $50 \mathrm{mmol} \mathrm{L}^{-1}$ $\mathrm{NH}_{3}$ solutions were used, recoveries between 91 and $107 \%$ were obtained with RSD values in the range of 3 to $10 \%$ for all analytes. In the same way, recoveries between 54 and $109 \%$, with RSDs from 5 to $11 \%$, were obtained for analytes after MIC by using $0.02,0.2$, and $0.9 \mathrm{mmol} \mathrm{L}^{-1}$ $\mathrm{H}_{2} \mathrm{O}_{2}$ as absorbing solutions. As can be observed, both $\mathrm{NH}_{3}$ solutions ( 25 and $50 \mathrm{mmol} \mathrm{L}^{-1}$ ) and $\mathrm{H}_{2} \mathrm{O}_{2}(0.2$ and $\left.0.9 \mathrm{mmol} \mathrm{L}^{-1}\right)$ solutions were suitable for the determination of $\mathrm{F}, \mathrm{Cl}, \mathrm{Br}$, and I by IC in WEEE after MIC. In this aspect, is important to notice that for higher analyte content (e.g., for keyboard sample 2, containing $12.5 \mathrm{mg} \mathrm{g}^{-1} \mathrm{Br}$ ), results were lower using the more diluted absorbing solutions ( $0.2 \mathrm{mmol} \mathrm{L}^{-1} \mathrm{H}_{2} \mathrm{O}_{2}$ and $25 \mathrm{mmol} \mathrm{L}^{-1} \mathrm{NH}_{3}$ solution). In these cases, suitable results were obtained using $50 \mathrm{mmol} \mathrm{L}^{-1}$ $\mathrm{NH}_{3}$ solution suggesting that this solution should be used for samples containing higher content of halogens.

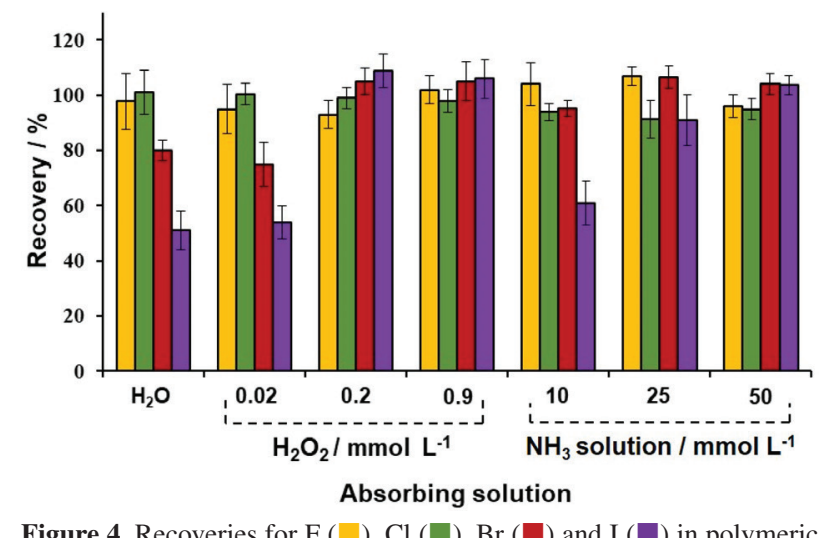
WEEE (from optical mouse) after MIC digestion using $\mathrm{H}_{2} \mathrm{O}, \mathrm{H}_{2} \mathrm{O}_{2}(0.02$, 0.2 and $\left.0.9 \mathrm{mmol} \mathrm{L}^{-1}\right)$ or diluted $\mathrm{NH}_{3}\left(10,25\right.$ and $\left.50 \mathrm{mmol} \mathrm{L}^{-1}\right)$ as absorbing solution. Determinations by IC (mean \pm standard deviation, $\mathrm{n}=3$ ).

Another important aspect of solutions used for the absorption of halogens for IC analyses is the $\mathrm{pH}$. In order to avoid possible damage to the column, the $\mathrm{pH}$ of the digest should be between 3 and $12 .{ }^{48}$ Thus, the $\mathrm{pH}$ values of the digests were checked after MIC. When 25 and $50 \mathrm{mmol} \mathrm{L}^{-1}$ $\mathrm{NH}_{3}$ solutions were used, $\mathrm{pH}$ values of the digests were between 5 and 6 . On the other hand, $\mathrm{pH}$ values lower than 2 were obtained when $0.02,0.2$, and $0.9 \mathrm{mmol} \mathrm{L}^{-1}$ $\mathrm{H}_{2} \mathrm{O}_{2}$ solutions were used to retain the analytes. As a consequence, and aiming to propose a simple and robust MIC method for halogens determination in many types of WEEE samples, $50 \mathrm{mmol} \mathrm{L} \mathrm{NH}_{3}$ solution was selected as the absorbing solution for subsequent studies. Figure 5 presents chromatograms obtained for a reference solution 
(100 $\left.\mu \mathrm{g} \mathrm{\textrm {L } ^ { - 1 }}\right)$ in $\mathrm{H}_{2} \mathrm{O}$ and for a final polymeric WEEE digest using $300 \mathrm{mg}$ of sample and diluted $\mathrm{NH}_{3}\left(50 \mathrm{mmol} \mathrm{L}^{-1}\right)$ as absorbing solution.

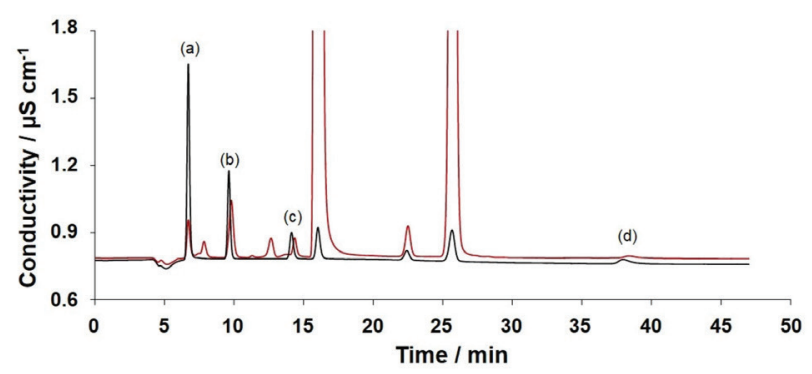

Figure 5. Chromatogram obtained for (-) a reference solution (100 $\mu \mathrm{g} \mathrm{L}^{-1}$ ) in $\mathrm{H}_{2} \mathrm{O}$ and (-) a digest obtained by MIC using $300 \mathrm{mg}$ of polymeric WEEE (from optical mouse) and diluted $\mathrm{NH}_{3}\left(50 \mathrm{mmol} \mathrm{L}^{-1}\right)$ as absorbing solution. (a) Fluoride, (b) chloride, (c) bromide and (d) iodide peaks.

\section{Accuracy and analytical figures of merit for MIC method}

After optimization, accuracy and general analytical figures of merit were evaluated for MIC. A good linear relationship throughout the selected concentration range (10 to $100 \mu \mathrm{g} \mathrm{L}^{-1}$ ) was obtained, and correlation coefficients $\left(\mathrm{R}^{2}\right)$ were better than 0.9997 for all halogens. Values for LOQ by IC were estimated by comparing the chromatogram obtained for a digested sample with a low concentration of analytes with a chromatogram obtained for an analytical blank. A signal-to-noise ratio of 10:1 was used as a parameter, and the final volume of the digest and sample mass were also taken into account. ${ }^{46} \mathrm{LOQs}$ by IC were $0.9,1.8,1.1$, and $1.5 \mu \mathrm{g} \mathrm{g}^{-1}$ for $\mathrm{F}, \mathrm{Cl}, \mathrm{Br}$, and $\mathrm{I}$, respectively. Using ICP-MS, LOQs $(10 \sigma)$ were calculated based on the standard deviation $(\sigma)$ of ten measurements of the analytical blank (a digest obtained by a procedure following all steps and reagents described for sample digestion, but without the sample). Also taking into account the final dilution and the sample mass, LOQs by ICP-MS were $43,0.06$, and $0.008 \mu \mathrm{g} \mathrm{g}^{-1}$ for $\mathrm{Cl}, \mathrm{Br}$, and I, respectively. The relatively low LOQ values obtained in this work can be considered as a consequence of the use of diluted absorbing solution (50 mmol L-1 $\mathrm{NH}_{3}$ solution) and the high digestion efficiency of MIC (carbon content in digests was lower than $10 \mathrm{mg} \mathrm{L}^{-1}$ ), with samples requiring no additional dilution. In addition, the relatively high mass of sample burned (up to $300 \mathrm{mg}$ ) also contributed to the low LOQ values.

Accuracy for MIC was evaluated using spike recoveries (for all analytes) and CRMs of polymers (ERM EC 680k and ERM EC 681k) for $\mathrm{Cl}$ and $\mathrm{Br}$, employing $6 \mathrm{~mL}$ of $50 \mathrm{mmol} \mathrm{L}-1 \mathrm{NH}_{3}$ solution. Spike recovery experiments were performed through the addition of a suitable amount of each reference solution ( $3.0 \mu \mathrm{g}$ for $\mathrm{F}$ and $6.0 \mu \mathrm{g}$ for $\mathrm{Cl}$, $\mathrm{Br}$, and I) on sample pellets $(300 \mathrm{mg}$ ) before combustion. Good recoveries (between 95 and 104\%) were achieved, with RSD in the range of 3 to $4 \%$. Table 1 shows the results of CRM digestion by MIC with further analyses by IC and ICP-MS.

Table 1. Results for $\mathrm{Cl}$ and $\mathrm{Br}$ in CRMs of polymers after digestion by MIC using $50 \mathrm{mmol} \mathrm{L}^{-1} \mathrm{NH}_{3}$ solution. Determinations by IC and ICP-MS (mean \pm standard deviation, $\mathrm{n}=3$ )

\begin{tabular}{lccccc}
\hline \multirow{2}{*}{ CRM } & \multicolumn{4}{c}{ Found value / $\left(\mu \mathrm{g} \mathrm{g}^{-1}\right)$} \\
\cline { 2 - 3 } \cline { 2 - 3 } \cline { 5 - 6 } & \multicolumn{2}{c}{$\mathrm{IC}$} & & \multicolumn{2}{c}{ ICP-MS } \\
\cline { 2 - 3 } ERM EC 680k & $102 \pm 8$ & $95 \pm 5$ & & $100 \pm 5$ & $94 \pm 5$ \\
ERM EC 681k & $820 \pm 40$ & $782 \pm 41$ & & $790 \pm 60$ & $724 \pm 55$ \\
\hline
\end{tabular}

${ }^{\mathrm{a} C e r t i f i e d}$ value for $\mathrm{Cl}$ and $\mathrm{Br}: 102.2 \pm 3.0$ and $96 \pm 4 \mu \mathrm{g} \mathrm{g}^{-1}$, respectively; 'certified value for $\mathrm{Cl}$ and $\mathrm{Br}: 800 \pm 50$ and $770 \pm 40 \mu \mathrm{g} \mathrm{g}^{-1}$, respectively. CRM: certified reference material; IC: ion chromatography; ICP-MS: inductively coupled plasma mass spectrometry; ERM: European Reference Materials.

In spite of the sample composition differing significantly for polyethylene, since e-waste is commonly composed by a blend of polymers, this was the only available CRM to evaluate in this work. Also, as no method is available to allow results comparison, the accuracy was considered by evaluating the quantitative spike recoveries and the agreement obtained for CRMs. Results obtained for $\mathrm{Cl}$ and $\mathrm{Br}$ by IC and ICP-MS after MIC presented no statistical difference with certified values ( $t$-test, $95 \%$ confidence level), with RSD in the range of 4 to $12 \%$ for both analytes. Therefore, MIC method was considered suitable for the quality control of $\mathrm{Cl}$ and $\mathrm{Br}$ in WEEE and, particularly for $\mathrm{Br}$, as an alternative for obtaining halogens concentrations following the RoHS directive.

Feasibility of the MIC method for polymeric WEEE digestion and further halogens determination

Under the conditions evaluated in this work, MAE and MAWD were unsuitable as a sample preparation method for bringing halogens in polymeric WEEE into solution for further determination. On the other hand, MIC was effective in completely destroying the polymeric matrix and suitable for the digestion of a relatively high amount of sample (up to $300 \mathrm{mg}$ ) with carbon content in the digests lower than $10 \mathrm{mg} \mathrm{L}^{-1}$. In addition, the suitable $\mathrm{pH}$ and low carbon content made digests suitable for analyses by both IC and ICP-MS. The total digestion time for MIC was only 25 min (faster than the other methods). Based on these results, MIC should be considered the method of 
Table 2. Results for halogens in polymeric WEEE after digestion by MIC (300 mg of sample and $50 \mathrm{mmol} \mathrm{L}^{-1} \mathrm{NH}_{3}$ solution). Determinations by IC (mean \pm standard deviation, $\mathrm{n}=3$ )

\begin{tabular}{|c|c|c|c|c|}
\hline Sample & $\mathrm{F} /\left(\mu \mathrm{g} \mathrm{g}^{-1}\right)$ & $\mathrm{Cl} /\left(\mu \mathrm{g} \mathrm{g}^{-1}\right)$ & $\mathrm{Br} /\left(\mu \mathrm{g} \mathrm{g}^{-1}\right)$ & $\mathrm{I} /\left(\mu \mathrm{g} \mathrm{g}^{-1}\right)$ \\
\hline Optical mouse & $<0.9$ & $18.9 \pm 3.6$ & $11.8 \pm 3.5$ & $<1.5$ \\
\hline Remote control of an air conditioner & $<0.9$ & $25.8 \pm 3.9$ & $<1.1$ & $<1.5$ \\
\hline Keyboard 1 & $<0.9$ & $40.3 \pm 1.7$ & $110 \pm 1$ & $<1.5$ \\
\hline Keyboard 2 & $<0.9$ & $467 \pm 37$ & $12500 \pm 100$ & $<1.5$ \\
\hline Mobile phone & $<0.9$ & $56.0 \pm 1.9$ & $300 \pm 2$ & $<1.5$ \\
\hline
\end{tabular}

choice for polymeric WEEE digestion for further halogens determination.

The proposed method was also applied to other polymeric WEEE sample digestion and further determination of halogens. Polymer samples segregated from a remote control of an air conditioner, keyboard, and a mobile phone were digested by MIC using a $50 \mathrm{mmol} \mathrm{L}^{-1}$ $\mathrm{NH}_{3}$ solution. In order to include the quantification of fluorine the determination was performed by IC (Table 2). Concentrations of $\mathrm{Cl}$ and $\mathrm{Br}$ in WEEE were in the range of 18.9 to 467 and 11.8 to $12500 \mu \mathrm{g} \mathrm{g}^{-1}$, respectively, except for a sample from the remote control of an air conditioner that presented a concentration of $\mathrm{Br}$ lower than the LOQ $\left(1.1 \mu \mathrm{g} \mathrm{g}^{-1}\right)$. The difference of values for $\mathrm{Cl}$ and $\mathrm{Br}$ could be due to the polymeric composition of each sample, linked to the quantity and type of flame retardant (halogenated compounds), since these compounds are used to improve the polymers performance. ${ }^{3}$ In addition, $F$ and I concentrations were lower than the LOQs $(0.9$ and $1.5 \mu \mathrm{g} \mathrm{g}^{-1}$, respectively) in all samples.

With regard to the higher content of $\mathrm{Br}$ in keyboard 2 sample, it was selected for an experiment using a more concentrated absorbing solution (diluted $\mathrm{NH}_{3}$, $100 \mathrm{mmol} \mathrm{L}^{-1}$ ) to check for robustness. No statistical difference for the results using this solution and the previously selected one $\left(50 \mathrm{mmol} \mathrm{L}^{-1}\right)$ was observed. Other halogens also presented the same behavior.

\section{Conclusions}

After a careful evaluation, this work demonstrated that the digestion of polymeric WEEE by MIC was suitable for further determination of halogens by IC or ICP-MS. It was observed that other methods suffer from their inherent limitations, mainly poor extraction efficiency and losses due to the use of acids. Although the MAE and MAWD methods can be considered as an alternative for many matrices, underestimated results for halogens in polymeric WEEE were found. Using MIC with diluted $\mathrm{NH}_{3}(50 \mathrm{mmol} \mathrm{L}-1)$ it was possible to achieve recoveries ranging from 95 to $104 \%$ for all analytes, with RSDs lower than $4 \%$. Agreement with certified values for CRMs was obtained. This method avoided the use of concentrated acids and allowed the complete digestion of up to $300 \mathrm{mg}$ of sample, resulting in digests that are compatible with IC determination allowing one single method for all halogens, as well as with ICP-MS for $\mathrm{Cl}, \mathrm{Br}$ and I.

\section{Supplementary Information}

Supplementary information is available free of charge at http://jbcs.sbq.org.br as PDF file.

\section{Acknowledgments}

The authors are grateful to the Fundação de Amparo à Pesquisa do Estado do Rio Grande do Sul (FAPERGS, grant 16/2551-0000182-0 for P. A. M.), Conselho Nacional de Desenvolvimento Científico e Tecnológico (CNPq, grant 14106812014-0 for J. S. S.), and Coordenação de Aperfeiçoamento de Pessoal de Nível Superior (CAPES, grant 1544449 for G. D. I.) for supporting this study.

\section{References}

1. Goosey, M. In Electronic Waste Management; Hester, R. E.; Harrison, R. M., eds.; The Royal Society of Chemistry: Cambridge, 2009, ch. 1.

2. European Union; Directive 2011/65/EU of the European Parliament and of the Council of 8 June 2011 on The Restriction of the Use of Certain Hazardous Substances in Electrical and Electronic Equipment; Official Journal of the European Union: Strasbourg, 2011, L 174/88.

3. Alaee, M.; Wenning, R. J.; Chemosphere 2002, 46, 579.

4. Restrepo, B. J.; Kannan, K.; Rapaport, D. P.; Rodan, B. D.; Environ. Sci. Technol. 2005, 39, 5177.

5. Segev, O.; Kushmaro, A.; Brenner, A.; Int. J. Environ. Res. Public Health 2009, 6, 478.

6. Darnerud, P. O.; Environ. Int. 2003, 29, 841.

7. Wit, C. A.; Chemosphere 2002, 46, 583. 
8. Altarawneh, M.; Saeed, A.; Al-Harahsheh, M.; Dlugogorski, B. Z.; Prog. Energy Combust. Sci. 2019, 70, 212.

9. Dimitrakakis, E.; Janz, A.; Bilitewski, B.; Gidarakos, E.; Waste Manage. 2009, 29, 2700.

10. McKay, G.; Chem. Eng. J. 2002, 86, 343.

11. Moraes, D. P.; Pereira, J. S. F.; Diehl, L. O.; Mesko, M. F.; Dressler, V. L.; Paniz, J. N. G.; Knapp, G.; Flores, E. M. M.; Anal. Bioanal. Chem. 2010, 397, 563.

12. Pereira, J. S. F.; Diehl, L. O.; Duarte, F. A.; Santos, M. F. P.; Guimarães, R. C. L.; Dressler, V. L.; Flores, E. M. M.; J. Chromatogr. A 2008, 1213, 249.

13. Mello, P. A.; Diehl, L. O.; Oliveira, J. S. S.; Muller, E. I.; Mesko, M. F.; Flores, E. M. M.; Spectrochim. Acta, Part B 2015, 105, 95.

14. Matusiewicz, H. In Comprehensive Analytical Chemistry; Mester, Z.; Sturgeon, R., eds.; Elsevier: Amsterdam, 2003, ch. 6.

15. Santos, M. C.; Nóbrega, J. A.; Cadore, S.; J. Hazard. Mater. 2011, 190, 833.

16. Smith, F. E.; Arsenault, E. A.; Talanta 1996, 43, 1207.

17. Oliveira, J. S. S.; Krzyzaniak, S. R.; Picoloto, R. S.; Bolzan, R. C.; Mello, P. A.; J. Braz. Chem. Soc. 2017, 28, 1657.

18. Todoli, J. L.; Gras, L.; Hernandis, V.; Mora, J.; J. Anal. At. Spectrom. 2002, 17, 142.

19. Hartwig, C. A.; Toralles, I. G.; Crizel, M. G.; Muller, A. L. H.; Picoloto, R. S.; Flores, E. M. M.; Mesko, M. F.; Anal. Methods 2014, 6, 7540 .

20. Hortas, V. R.; Pineiro, A. M.; Barrera, P. B.; Talanta 2009, 79, 947.

21. Aldrian, A.; Ledersteger, A.; Pomberger, R.; Waste Manage. 2015, 36, 297.

22. Fink, H.; Panne, U.; Theisen, M.; Niessner, R.; Probst, T.; Lin, X.; J. Anal. Chem. 2000, 368, 235.

23. Taurino, R.; Cannio, M.; Mafredini, T.; Pozzi, P.; Environ. Technol. 2014, 35, 3147.

24. Mans, C.; Hanning, S.; Simons, C.; Wegner, A.; Janben, A.; Kreyenschmidt, M.; Spectrochim. Acta, Part B 2007, 62, 116.

25. Pöhlein, M.; Urpi Bertran, R.; Wolf, M.; van Eldik, R.; Anal. Bioanal. Chem. 2009, 394, 583.

26. Seefield, E. W.; Robinson, J. W.; Anal. Chim. Acta 1960, 23, 301.

27. Burfield, D. R.; Ng, S. C.; J. Chem. Educ. 1984, 61, 917.

28. Costa, V. C.; Picoloto, R. S.; Hartwig, C. A.; Mello, P. A.; Flores, E. M. M.; Mesko, M. F.; Anal. Bioanal. Chem. 2015, 407, 7957.

29. Pereira, J. S. F.; Knorr, C. L.; Pereira, L. S. F.; Moraes, D. P.; Paniz, J. N. G.; Flores, E. M. M.; Knapp, G.; J. Anal. At. Spectrom. 2011, 26, 1849.
30. Antes, F. G.; Santos, M. D. P.; Guimarães, R. C. L.; Paniz, J. N. G.; Flores, E. M. M.; Dressler, V. L.; Anal. Methods 2011, $3,288$.

31. Iop, G. D.; Krzyzaniak, S. R.; Silva, J. S.; Flores, E. M. M.; Costa, A. B.; Mello, P. A.; J. Anal. At. Spectrom. 2017, 32, 1789.

32. Knapp, G.; Maichin, B.; Fecher, P.; Hasse, S.; Schramel, P.; J. Anal. Chem. 1998, 362, 508.

33. Mesko, M. F.; Costa; V. C.; Picoloto, R. S.; Bizzi, C. A.; Mello, P. A.; J. Anal. At. Spectrom. 2016, 31, 1243.

34. Gamallo-Lorenzo, D.; Barciela-Alonso, M. C.; Moreda-Piñeiro, A.; Bermejo-Barrera, A.; Bermejo-Barrera, P.; Anal. Chim. Acta 2005, 542, 287.

35. Tagami, K.; Uchida, S.; Hirai, I.; Tsukada, H.; Takeda, H.; Anal. Chim. Acta 2006, 570, 88.

36. Rose, M.; Miller, P.; Baxter, M.; Appleton, G.; Crews, H.; Croasdale, M.; J. Environ. Monit. 2001, 3, 361.

37. Mello, P. A.; Barin, J. S.; Duarte, F. A.; Bizzi, C. A.; Diehl, L. O.; Muller, E. I.; Flores, E. M. M.; Anal. Bioanal. Chem. 2013, 405, 7615.

38. Shoeib, M.; Ahrens, L.; Jantunen, L.; Harner, T.; Atmos. Environ. 2014, 99, 140.

39. King, E. E.; Barclay, D. In Comprehensive Analytical Chemistry; Mester, Z.; Sturgeon, R. E., eds.; Elsevier: Amsterdam, 2003, ch. 8 .

40. Mester, Z.; Sturgeon, R.; Sample Preparation for Trace Element Analysis, $1^{\text {st }}$ ed.; Elsevier: Amsterdam, 2003.

41. Arruda, M. A. Z.; Trends in Sample Preparation, $1^{\text {st }}$ ed.; Nova Science: New York, 2007.

42. Miskolczi, N.; Hall, W. J.; Borsodi, N.; Williams, P. T.; Angyal, A.; Microchem. J. 2011, 99, 60.

43. Vázquez, A. S.; Costa-Fernandez, J. M.; Encinar, J. R.; Pereiro, R.; Sanz-Medel, A.; Anal. Chim. Acta 2008, 623, 140.

44. Ritter, A.; Michel, E.; Schmid, M.; Affolter, S.; Polym. Test. 2004, 23, 467.

45. Besecker, K. D.; Rhoades, C. B.; Jones, B. T.; Barnes, K. W.; At. Spectrosc. 1998, 19, 55.

46. Sakurai, H.; Noro, J.; Kawase, A.; Fujinami, M.; Oguma, K.; Anal. Sci. 2006, 22, 225.

47. Di Narda, F.; Toniolo, R.; Bontempelli, G.; Anal. Chim. Acta 2001, 436, 245.

48. Metrohm; The Column Program; Metrohm AG: Hensau, 2018, p. 66.

Submitted: February 24, 2019

Published online: June 13, 2019 